\title{
Desenvolvimento de concretos refratários multifuncionais
}

\section{(Development of multifunctional refractory castables)}

\author{
A. R. Studart, R. G. Pileggi, V. C. Pandolfelli \\ Departamento de Engenharia de Materiais \\ Universidade Federal de S. Carlos - UFSCar \\ Rod. Washington Luiz, km 235, C. P. 676, S. Carlos, SP, 13565-905 \\ tel.:0XX-16-260.8253,fax:0XX-16-261.5404 \\ pars@iris.ufscar.br,vicpando@power.ufscar.br
}

\begin{abstract}
Resumo
A facilidade de aplicação dos concretos tem sido uma das principais justificativas da substituição de peças moldadas por refratários monolíticos. Todavia, as inúmeras técnicas disponíveis para aplicação dos monolíticos têm resultado em uma diversificação muito acentuada das classes de concreto refratário (p. ex., vibrados, projetados, auto-escoantes, "shotcreting"). Em virtude disso, há atualmente uma crescente demanda por concretos de maior versatilidade, denominados multifuncionais, que possibilitem a utilização das mais variadas técnicas para aplicação. No entanto, ainda questiona-se se a versatilidade dos concretos multifuncionais durante a aplicação também implica em benefícios com relação à etapa de mistura e ao seu desempenho a altas temperaturas. O objetivo deste trabalho é identificar os requisitos necessários para a obtenção de concretos multifuncionais, e comparar o seu comportamento reológico e resistência à fluência a quente com concretos normalmente aplicados com técnicas específicas de instalação. Os resultados indicam que a distribuição granulométrica é a principal determinante da característica multifuncional de concretos de alta alumina com ultra-baixo teor de cimento.
\end{abstract}

Palavras-chave: concreto, refratário, multifuncional, alumina, granulometria.

\section{INTRODUÇÃO}

A crescente demanda das indústrias siderúrgicas, petroquímicas e de cimento por refratários monolíticos tem estimulado o desenvolvimento de diversas técnicas de instalação, com o intuito de minimizar a introdução de defeitos no revestimento e atender às exigências específicas de cada tipo de equipamento. Tais exigências são determinadas, de um modo geral, pela região do equipamento que se deseja revestir, facilidade de acesso a tal região, disponibilidade de vibradores e mão-de-obra especializada, custo, formato do molde, entre outros.

Para facilitar a aplicação do refratário diante de circunstâncias tão distintas, diversas categorias de concretos refratários têm sido desenvolvidas, dentre as quais se destacam os concretos socados, vibrados, auto-escoantes, bombeáveis e projetáveis.

\begin{abstract}
The ease of installation of castables has been one of the major reasons for the replacement of shaped materials by monolithics refractories. However, the extensive number of techniques available for the installation of monolithics has broadened in excess the classes of refractory castables in the market (i.e, vibratable, gunning, self-flow, shot-creting). Therefore, a significant demand for more versatile castable has emerged in the latest years. Expectations lay on the development of multifunctional castables that could be installed using most of the large variety of methods available. Nevertheless, it is still unknown if the versatility of multifunctional castables during installation would also result in benefits regarding the mixing step prior to application and the high temperature performance. The objective of this paper is to identify the main requisites necessary to obtain multifunctional castables and compare their rheological behavior and creep resistance at high temperature with that of castables installed with specific application techniques. Results indicate that the particle size distribution mainly determines the multifunctional feature of high-alumina ultra-low-cement castables.
\end{abstract}

Keywords: castable, refractory, multifunctional, alumina, particle size distribution.

No entanto, tamanha variedade de classes de concretos requer das indústrias a manutenção de elevados estoques de materiais refratários, que resultam em custos adicionais aos usuários. Além disso, diferentemente das peças conformados, os concretos geralmente apresentam um prazo de validade relativamente curto, tornando desvantajoso o armazenamento de uma grande variedade de composições. Isso tem justificado os esforços direcionados ao desenvolvimento de concretos, denominados multifuncionais, que possibilitam a aplicação através de diferentes técnicas, de acordo apenas com o teor de água adicionado durante a mistura [1].

Tendo em vista que cada classe de concretos é geralmente caracterizada por um determinado perfil de distribuição de tamanho de partículas, esse trabalho tem como objetivo determinar a curva granulométrica mais adequada para a obtenção de concretos refratários multifuncionais. 
Uma vez estabelecida tal distribuição granulométrica, resta avaliar se as vantagens que caracterizam os concretos multifuncionais durante a etapa de aplicação também se estendem às propriedades do refratário a altas temperaturas.

Desta forma, avaliou-se no presente trabalho o efeito da distribuição de tamanho de partículas sobre a etapa de mistura, o comportamento reológico e a taxa de fluência a alta temperatura de concretos refratários de alta alumina com ultra-baixo teor de cimento.

\section{MATERIAIS E MÉTODOS}

Concretos com distribuições de tamanho de partículas distintas foram preparados baseado no modelo de empacotamento de Andreasen. Os concretos podem ser diferenciados quanto ao coeficiente de distribuição q de sua curva granulométrica $(0,21 ; 0,26$ e 0,31), conforme indicado na Fig. 1.

As matérias-primas utilizadas para a preparação dos concretos, incluindo seus respectivos teores, são apresentadas na Tabela I. Vale ressaltar que, embora a fração total de matriz dos concretos se reduza com o aumento do coeficiente q, a proporção entre os teores

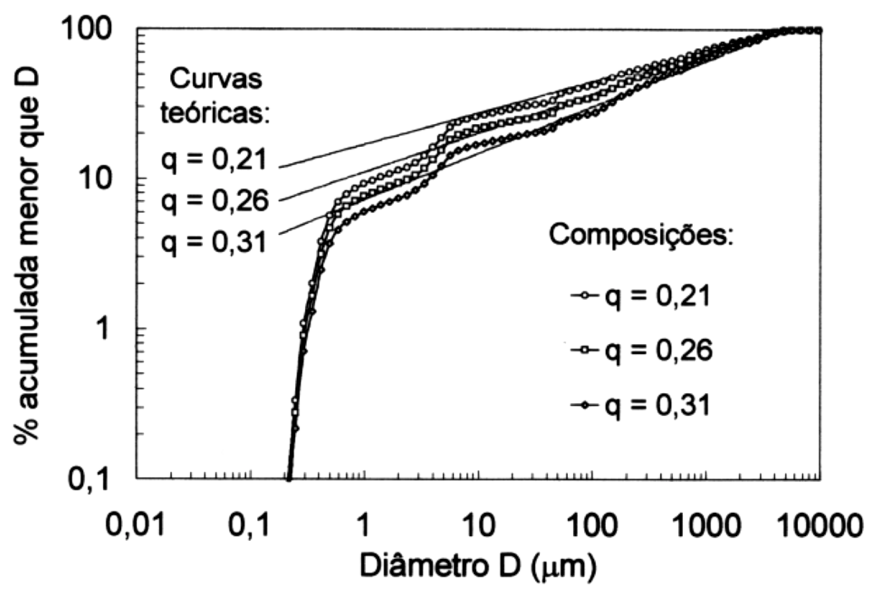

Figura 1: Distribuição de tamanho de partículas dos concretos avaliados. [Figure 1: Particle size distribution of the castables evaluated in this work]. das aluminas calcinadas A-1000SG e A-3000FL foi mantida constante para todas as composições estudadas.

Ácido cítrico, em teor ótimo previamente estipulado $\left(0,36 \mathrm{mg} / \mathrm{m}^{2}\right)$, foi utilizado como dispersante dos concretos. A mistura do concreto foi efetuada adicionando-se primeiramente apenas uma fração do teor total de água planejado para a composição, conforme sugerido recentemente [2]. Essa quantidade inicial de água foi adicionada utilizando uma vazão constante de cerca de $8 \mathrm{~g} / \mathrm{s}$ e corresponde a teores de $11 \%, 12 \%$ e $13 \%$-vol. para as composições com q igual a 0,31; 0,26 e 0,21, respectivamente. Após a adição desses teores de água, manteve-se o concreto sob rotação constante (33 rpm) até a ocorrência do fenômeno de "virada", após o qual a quantidade restante de água da composição foi incorporada. A etapa de mistura foi avaliada com o auxílio de um reômetro especialmente desenvolvido para concretos [3], através do qual foi possível detectar o torque aplicado durante a mistura a uma rotação constante de $33 \mathrm{rpm}$.

A fluidez de concretos preparados com teores de água entre $13 \%$ e $16 \%$-vol. foi determinada sem aplicação de vibração, de acordo com a norma ASTM C-860 adaptada para concretos auto-escoantes.

Corpos de prova cilíndricos com diâmetro externo de $\sim 50 \mathrm{~mm}$ foram moldados e, em seguida, sinterizados a $1650^{\circ} \mathrm{C}$ por 24 horas para a determinação da taxa de fluência dos concretos. $\mathrm{O}$ ensaio de fluência foi efetuado a $1600^{\circ} \mathrm{C}$ utilizando uma taxa compressiva constante de 0,2 $\mathrm{MPa}$.

\section{RESULTADOS E DISCUSSÃO}

\section{Mistura:}

A etapa de mistura é de extrema importância durante a aplicação dos concretos refratários, uma vez que afeta diretamente o tempo de parada dos equipamentos durante operações de reparo ou substituição do revestimento. Concretos que sejam rapidamente misturados e que exijam misturadores de menor potência são sempre os mais adequados.

O torque aplicado aos concretos durante a mistura é apresentado na Fig. 2, como um indicativo da resistência do concreto ao cisalhamento imposto pelo misturador. A área sob as curvas de torque em função do tempo foi tomada como um indicativo da ener-

Tabela I: Formulação e características gerais dos concretos preparados.

\begin{tabular}{|c|c|c|c|c|}
\hline \multicolumn{2}{|c|}{$\%$-vol. (\%-peso) } & $q=0,21$ & $q=0,26$ & $q=\mathbf{0 , 3 1}$ \\
\hline \multicolumn{2}{|c|}{ Alumina eletrof. branca $(4 / 10-200 \mathrm{~F})^{\wedge}$} & $75,1(75,2)$ & $79,2(78,3)$ & $83,3(82,6)$ \\
\hline \multirow{2}{*}{$\begin{array}{l}\text { Aluminas } \\
\text { calcinadas }\end{array}$} & A-1000 SG & $8,4(8,4)$ & $6,9(6,9)$ & $5,5(5,5)$ \\
\hline & A-3000 FL & $15,3(15,4)$ & $12,6(13,7)$ & $10,0(10,9)$ \\
\hline \multicolumn{2}{|c|}{ Cimento CA $270^{\wedge}$} & $1,25(1,00)$ & $1,20(1,00)$ & $1,24(1,00)$ \\
\hline \multicolumn{2}{|c|}{ Área superficial total $\left(\mathrm{m}^{2} / \mathrm{g}\right)$} & 8,37 & 7,51 & 6,55 \\
\hline \multicolumn{2}{|c|}{ Porosidade teórica total (\%) } & 9,34 & 8,31 & 6,87 \\
\hline \multirow[t]{4}{*}{ MPT $(\mu \mathrm{m})$} & $13 \%$-v. água & - & - & 72,3 \\
\hline & $14 \%$-v. água & 132,6 & 105,0 & 75,6 \\
\hline & $15 \%$-v. água & 136,5 & 108,6 & 79,0 \\
\hline & $16 \%$-v. água & 140,5 & 112,4 & - \\
\hline
\end{tabular}

${ }^{\wedge}$ Alcoa Alumínio S.A.

${ }^{\triangleleft}$ Após adição de 14\%-vol. de água 
gia empregada durante a mistura. Pode-se observar que os níveis de torque aplicado e a energia de mistura diminuem à medida que se aumenta o coeficiente q da distribuição granulométrica. Essa tendência está relacionada com a área superficial total das composições (Tabela I). Concretos com superior área superficial são mais susceptíveis à atuação das forças de capilaridade durante a mistura. Tais forças resultam da formação de um filme líquido entre as partículas que as mantêm atraídas entre si. Quanto mais elevada a área superficial de um sistema particulado, maior é a somatória das forças de capilaridade atuantes e, portanto, maiores são as tensões necessárias para deslocar as partículas entre si e proporcionar a mistura [4].

Desta forma, os superiores níveis de torque e energia de mistura observados para os concretos com inferior coeficiente q, podem ser atribuídos à maior área superficial dessas composições. $\mathrm{O}$ efeito mais pronunciado das forças de capilaridade ocorre quando todas as partículas estão recobertas por um fino filme de líquido, resultando em um pico de torque normalmente conhecido como a "virada" do concreto.

Composições com inferior área superficial também requerem menor teor de água para o recobrimento das partículas (Fig. 2). Sendo assim, o tempo necessário para recobrir as partículas e atingir o pico de torque durante a mistura também é função da área superficial da composição. A Fig. 2 mostra que o aumento do coeficiente q reduz o tempo até a "virada" do concreto, como resultado da diminuição da área superficial total do concreto.

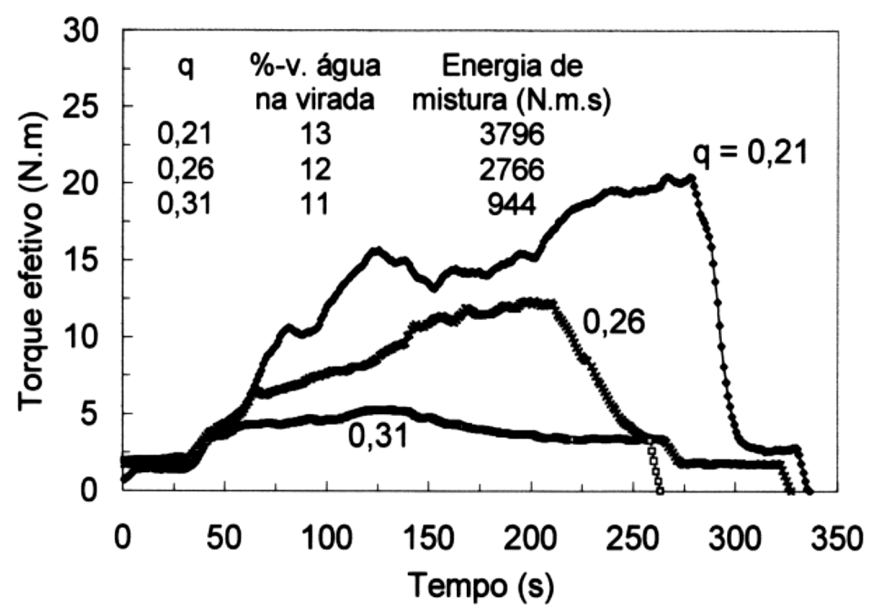

Figura 2: Torque aplicado aos concretos durante a etapa de mistura. [Figure 2: Torque applied to castables during the mixing process].

\section{Comportamento reológico:}

A Fig. 3 apresenta as medidas de fluidez dos concretos em função do teor de água para diferentes valores de q. Para auxiliar a análise dos resultados, o gráfico foi arbitrariamente subdividido em regiões que indicam os valores de fluidez característicos de concretos socados, vibrados e auto-escoantes.

A Tabela I mostra que a alteração do coeficiente q da distribuição granulométrica dos concretos resultou em significativas alterações na faixa de valores de MPT (Maximum Paste Thickness) das composições. Sendo uma estimativa da distância média de separação entre os agregados, o MPT pode indicar o grau de interferência entre as partículas grosseiras do concreto durante o escoamento. Têmse observado que, de um modo geral, o aumento de MPT confere superior fluidez aos concretos [5]. Os resultados da Fig. 3 serão analisados com base nos valores de MPT das composições, assumindose que esse foi o parâmetro determinante da fluidez dos concretos.

Observa-se que a composição $q=0,31$ apresentou valores de fluidez bastante reduzidos, típicos de concretos socados. Isso pode ser atribuído aos baixos valores de MPT desses concretos $(72,3 \mu \mathrm{m}-$ $79,0 \mu \mathrm{m})$, decorrente principalmente do seu reduzido teor de matriz (Tabela I).

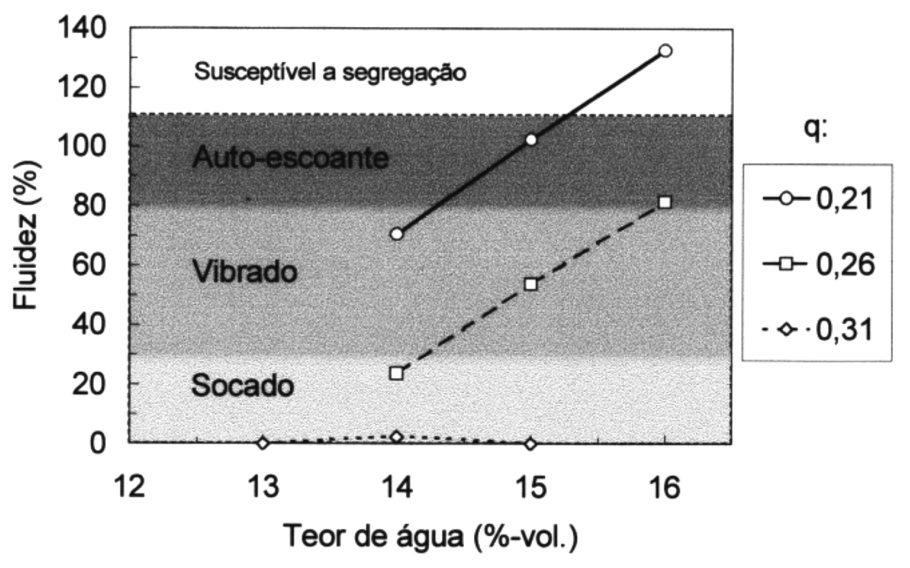

Figura 3: Fluidez dos concretos em função do teor de água para diferentes valores do coeficiente q.

[Figure 3: Castable flowability as a function of water content for different values of the modulus of distribution q].

A composição $q=0,21$, por outro lado, apresentou MPT entre 132,6 (e 140,5 $\mu \mathrm{m}$, o que resultou em valores de fluidez significativamente superiores. Nesse caso, a variação do teor de água adicionado permitiu que se obtivesse concretos vibrados (14\%-vol.) ou auto-escoantes (15\%-vol.) com uma única composição. Tudo indica que a adição de teores de água superiores (p. ex., 16\%-vol.) poderia favorecer a ocorrência de segregação das partículas grosseiras do concreto, em decorrência da acentuada redução da viscosidade da matriz (Fig. 3). Através da extrapolação dos resultados de fluidez da Fig. 3 pode-se inferir também que, mesmo com a adição do teor mínimo de água para a "virada" (13\%-vol.), não seria possível obter concretos socados utilizando o coeficiente $q=0,21$.

Os concretos com coeficiente $q=0,26$, por sua vez, apresentaram valores de MPT (105,0 (a 112,4 $\mu \mathrm{m})$ e fluidez intermediários, que possibilitaram a obtenção de concretos socados (14\%-vol. água), vibrados (15\%-vol. água) ou auto-escoantes (16\%-vol. água). Essa característica satisfaz o requisito inicial que define os concretos multifuncionais, indicando que o coeficiente de distribuição $\mathrm{q}=0,26$ parece ser o mais adequado para a obtenção desse tipo de concreto.

Os concretos com coeficiente $q=0,26$ também foram avaliados quanto à facilidade de bombeamento, com o auxílio do reômetro anteriormente empregado no estudo da etapa de mistura. Para simular as condições de cisalhamento impostas durante o bombeamento, submeteu-se os concretos a um ciclo de solicitação entre 2 e 75 rpm, como indicado na Fig. 4.

Os resultados mostram que o aumento do teor de água dos concretos reduz significativamente o nível de torque necessário para 
manter a rotação aplicada constante. Comparando os resultados obtidos com o comportamento reológico de concretos bombeáveis comerciais, verifica-se que a adição de $16 \%$-vol. de água à composição $\mathrm{q}=0,26$ reduz os níveis de torque para uma faixa de valores adequada para o bombeamento [6]. Essa característica reforça o caráter multifuncional dos concretos preparados com coeficiente $\mathrm{q}=0,26$.

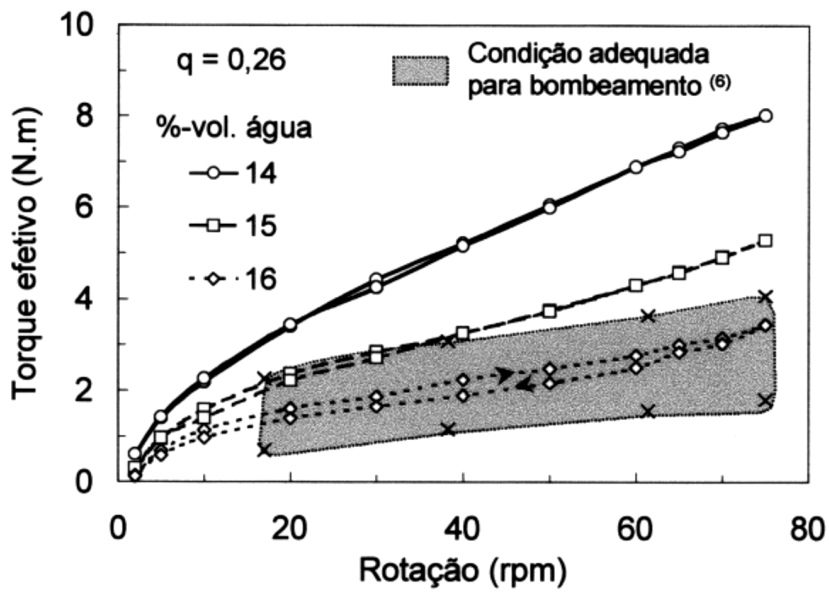

Figura 4: Torque aplicado aos concretos com coeficiente $q=0,26$, em função da rotação, para diferentes teores de água.

[Figure 4: Torque applied to castables prepared with $q=0.26$ as a function of rotation for different water contents].

\section{Fluência a alta temperatura:}

Os resultados de fluidez mostraram que o escoamento do concreto é favorecido pelo aumento da distância de separação entre os agregados (superior MPT). No entanto, o aumento dessa distância exige a introdução de teores superiores de aluminas calcinadas e cimento (matriz) aos concretos (Tabela I). Tendo em vista que as partículas finas são mais susceptíveis aos mecanismos de deformação por fluência a altas temperaturas, cabe avaliar se o aumento do teor de matriz nas composições com inferior coeficiente q pode também reduzir a resistência à fluência dos concretos.

Para avaliar essa questão, comparou-se a taxa de fluência dos concretos com diferentes valores de q, preparados com um teor fixo de água (14\%-vol.), como mostra a Fig. 5. Pode-se observar que, apesar dos diferentes teores iniciais de matriz (Tabela I), as composições apresentaram comportamento bastante similar com relação à fluência a alta temperatura. Embora os concretos com 14\%-vol. de água tenham apresentado porosidade aparente distinta após a queima (Tabela II), a correção dos valores de taxa de fluência para a condição de porosidade nula resultou na mesma tendência observada na Fig. 5.

A avaliação da microestrutura dos concretos para a determinação da distribuição de tamanho de grãos obtida após a sinterização possibilitaria uma análise mais criteriosa dos resultados de fluência. No entanto, tudo indica que a etapa de sinterização dos concretos originou distribuições de tamanho de grãos bastante similares entre as composições com diferentes valores de q. De acordo com essa hipótese, os concretos com superior teor de matriz (inferior q) teriam apresentado superior taxa de crescimento de grãos durante a queima em relação às demais composições. A superior área su- perficial das composições com inferior q (Tabela I) fortalece essa hipótese, uma vez que a área superficial é a força motriz dos processos de densificação e crescimento de grão que ocorrem durante a queima.

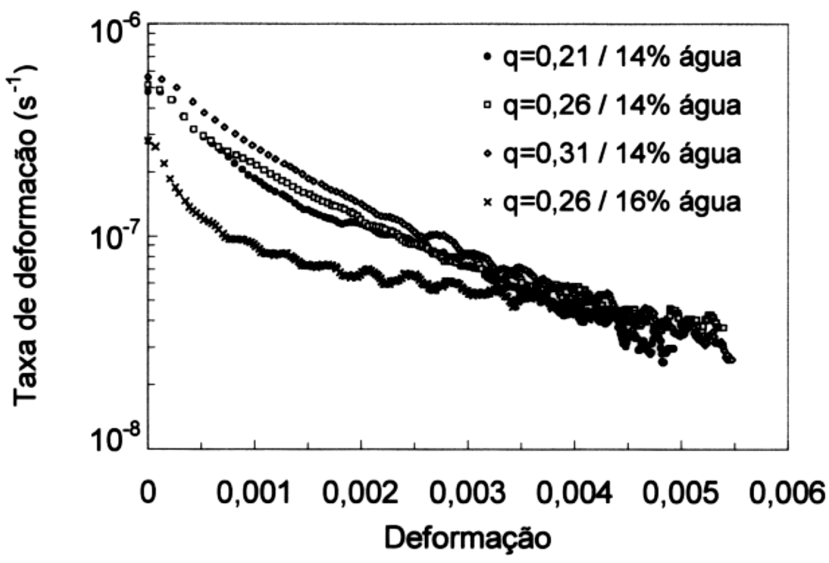

Figura 5: Taxa de fluência dos concretos a $1600{ }^{\circ} \mathrm{C}$ em função da deformação. [Figure 5: Creep rate of castables at $1600^{\circ} \mathrm{C}$ as a function of the total strain].

O aumento do grau de densificação dos concretos para inferiores valores de q (Tabela II) é mais um indicativo de que os mecanismos de sinterização (incluindo crescimento de grão) foram mais pronunciados nos concretos com superior teor de matriz.

A Fig. 5 mostra que o aumento do teor de água da composição $q=0,26$ de $14 \%$-vol. para 16\%-vol. elevou a resistência à fluência do concreto na fase inicial de deformação. Apesar disso, a taxa de fluência desses concretos tende a valores bastante similares na região do gráfico correspondente ao regime estacionário de deformação (onde a taxa de fluência é constante).

Vale destacar ainda que a adição de superiores teores de água aos concretos com $q=0,26$ para atingir a condição auto-escoante (Fig. 3) não deteriorou a resistência à fluência do material quando comparado à composição que atinge níveis similares de fluidez $(q=0,21)$, porém com inferior teor de água (14\%-vol.).

Tabela II: Porosidade aparente dos concretos com 14\%-vol. de água antes e após a queima.

\begin{tabular}{|c|c|c|c|}
\hline \multirow{2}{*}{ Composição } & \multicolumn{2}{|c|}{ Porosidade aparente $(\%)$} & \multirow{2}{*}{$\begin{array}{c}\text { Grau de } \\
\text { densificação } \\
(\%)^{\wedge}\end{array}$} \\
\hline & $\begin{array}{c}\text { Antes da } \\
\text { queima }\end{array}$ & $\begin{array}{c}\text { Após } \\
\text { queima }\end{array}$ & \\
\hline$q=0,21$ & 11,95 & 8,22 & 31,2 \\
\hline$q=0,26$ & 11,89 & 9,28 & 22,0 \\
\hline$q=0,31$ & 11,94 & 9,98 & 16,4 \\
\hline
\end{tabular}

^ Parâmetro arbitrariamente definido como sendo igual a $100 \% x$ $\left(P A_{\text {antes }}-P A_{\text {após }}\right) / P A_{\text {antes }}$

\section{CONCLUSÕES}

A distribuição de tamanho de partículas afeta diretamente o comportamento reológico dos concretos, determinando as técnicas possíveis para a sua aplicação.

Curvas de distribuição de tamanho de partículas baseadas no 
modelo de Andreasen com coeficiente q próximo a 0,26 possibilitaram a obtenção de concretos, denominados multifuncionais, que podem ser aplicados através de diferentes técnicas (socagem, vibração ou auto-fluência), dependendo apenas do teor de água adicionado.

A comparação dos resultados obtidos nesse trabalho com o comportamento reológico de concretos refratários comerciais mostrou que o concreto multifuncional obtido também apresenta características propícias para o bombeamento.

O coeficiente de Andreasen (q) também apresentou influência significativa sobre o comportamento do concreto durante a etapa de mistura. Composições caracterizadas por inferiores valores de q requerem a utilização de misturadores de alta energia e exigem um maior período de tempo para a conclusão dessa etapa. Por apresentarem características intermediárias, os concretos multifuncionais $(\mathrm{q}=$ 0,26 ) requisitam misturadores de médio porte durante a etapa de mistura.

Embora o teor de matriz dos concretos se altere significativamente em função do coeficiente de distribuição q, não foram observadas diferenças significativas entre os concretos com granulometrias distintas com relação à taxa de fluência a alta temperatura. Isso indica que os concretos multifuncionais apresentam desempenho a altas temperaturas similar ao observado para composições aplicadas com técnicas específicas de instalação (p. ex., socagem ou vibração).

\section{AGRADECIMENTOS}

Os autores agradecem à FAPESP, CAPES, CNPq e Alcoa Alumínio pelo apoio para a realização deste trabalho.

\section{REFERÊNCIAS}

[1] J. Mosser, G. Karhut, in Proceedings Unified International Technical Conference on Refractories (UNITECR), Berlin (1999) 25-30.

[2] R. G. Pileggi, A. R. Studart, V. C. Pandolfelli. Trabalho apresentado no $44^{\circ}$ Congresso Brasileiro de Cerâmica, Águas de S. Pedro, SP (2000) 12.

[3] R. G. Pileggi, A. E. Paiva, V. C. Pandolfelli, J. Gallo, Am. Ceram. Soc. Bull. 79, 1 (2000) 54.

[4] N. Harnby, M. F. Edwards, A. W. Nienow, Mixing in the Process Industries. $2^{\text {nd }}$. Ed., Butterworth-Heinemann, Oxford (1997) 79.

[5] P. Bonadia, A. R. Studart, R. G. Pileggi, V. C. Pandolfelli, Am. Ceram. Soc. Bull. 78, 3 (1999) 57.

[6] R. G. Pileggi, A. R. Studart, C. Pagliosa, V. C. Pandolfelli, Cerâmica 46, 300 (2000) 176.

(Rec. 09/09/00, Ac. 10/11/00) 